\title{
THE INFLUENCE OF NUTRIENT SUPPLY AND CELL DENSITY ON THE GROWTH AND SURVIVAL OF INTERVERTEBRAL DISC CELLS IN 3D CULTURE
}

\author{
Simon Stephan ${ }^{1,2,3}$, W. Eustace Johnson ${ }^{1,2,4}$ and Sally Roberts ${ }^{1,2, *}$ \\ ${ }^{1}$ Spinal Studies, Robert Jones \& Agnes Hunt Orthopaedic Hospital, Oswestry, Shropshire, UK \\ ${ }^{2}$ Institute for Science and Technology in Medicine, Keele University, Staffordshire, UK \\ ${ }^{3}$ Research School of Translational Medicine, University of Manchester, Wythenshawe Hospital, Southmoor Road, \\ Manchester, UK \\ ${ }^{4}$ School of Life \& Health Sciences, Aston University, Birmingham, UK
}

\begin{abstract}
The adult human intervertebral disc (IVD) is normally avascular. Changes to the extracellular matrix in degenerative disc disease may promote vascularisation and subsequently alter cell nutrition and disc homeostasis. This study examines the influence of cell density and the presence of glucose and serum on the proliferation and survival of IVD cells in 3D culture.

Bovine nucleus pulposus (NP) cells were seeded at a range of cell densities $\left(1.25 \times 10^{5}-10^{6}\right.$ cells $\left./ \mathrm{mL}\right)$ and cultured in alginate beads under standard culture conditions (with $3.15 \mathrm{~g} / \mathrm{L}$ glucose and $10 \%$ serum), or without glucose and/or $20 \%$ serum. Cell proliferation, apoptosis and cell senescence were examined after 8 days in culture.

Under standard culture conditions, NP cell proliferation and cluster formation was inversely related to cell seeding density, whilst the number of apoptotic cells and enucleated "ghost" cells was positively correlated to cell seeding density. Increasing serum levels from $10 \%$ to $20 \%$ was associated with increased cluster size and also an increased prevalence of apoptotic cells within clusters. Omitting glucose produced even larger clusters and also more apoptotic and senescent cells.

These studies demonstrate that NP cell growth and survival are influenced both by cell density and the availability of serum or nutrients, such as glucose. The observation of clustered, senescent, apoptotic or "ghost" cells in vitro suggests that environmental factors may influence the formation of these phenotypes that have been previously reported in vivo. Hence this study has implications for both our understanding of degenerative disc disease and also cell-based therapy using cells cultured in vitro.
\end{abstract}

Keywords: Degenerative disc disease, regenerative therapy, glucose, serum, cell clusters, alginate beads, Ki67, SA- $\beta$ galactosidase.

*Address for correspondence:

Sally Roberts

Robert Jones \& Agnes Hunt Orthopaedic Hospital

Spinal Studies, ARC/TORCH Building

Oswestry, Shropshire, SY10 7AG, UK

E-mail: Sally.Roberts@rjah.nhs.uk

\section{Introduction}

The intervertebral discs (IVD) are the main joints of the spinal column and lie between the vertebral bodies. Disorders related to IVD degeneration are common causes of morbidity or deterioration of quality of life (Waddell, 1996). During aging and degeneration, the IVD exhibits extensive morphological changes such as fibrosis of the nucleus pulposus, disorganised lamellae within the annulus fibrosus and calcification of the vertebral endplates (Bernick and Caillet, 1982; Benneker et al., 2005; Roberts et al., 2006b). Some studies have suggested that these changes are the result of tissue remodelling mediated by disc cells (Adams and Roughley, 2006) which occur at a low cell density of approximately 4000 cells/ $\mathrm{mm}^{3}$ in the healthy nucleus pulposus (Maroudas et al., 1975), with increasing death of cells associated with aging and disc degeneration (Gruber and Hanley, 1998; Boos et al., 2002). The metabolism of IVD cells is important to the functioning of the tissue. It has been suggested that nutrient deprivation may reduce cell viability in the disc and therefore be a pathway leading to disc degeneration (Bibby and Urban, 2004; Benneker et al., 2005). Changes in cell behaviour observed in degenerate human IVDs include cell cluster formation (Johnson et al., 2001), cell senescence (Roberts et al., 2006a; Le Maitre et al., 2007) and apoptosis (Sitte et al., 2010). It has been shown that reduced levels of glucose and oxygen, combined with other environmental conditions present in the inner parts of human IVDs (i.e., decreased $\mathrm{pH}$ and decreased osmolarity), decreases the anabolic activity of IVD cells (Ohshima and Urban, 1992; Ishihara et al., 1997). The disc's avascularity has long been considered to influence IVD cell function (Maroudas et al., 1975), a view supported by in vitro studies.

Few studies, however, have examined the influence of nutrient factors on the proliferation and survival of IVD cells, particularly in a 3D environment. It has been suggested that growth factors may be unlikely to enter the inner regions of the healthy IVD via diffusion from the peripheral vasculature (Holm et al., 1981; Grunhagen et al., 2006), since larger, globular proteins are likely to have a lower diffusion rate than smaller, more linear molecules (as has been shown in the cartilage endplate (Roberts et al., 1996)). Disc degeneration is often characterised by increased vascularisation (Kauppila 1995), as well as the appearance of cell clusters that are Ki67 antigen positive, indicating localised cellular proliferation (Johnson et al., 2001). Hence, the provision of serum-derived factors to 
IVD cells may increase in pathological IVDs and could play an important role in regulating IVD cell behaviour.

In this study, we have examined the influence of cell seeding density, serum concentration and glucose availability on the growth pattern of bovine IVD cells encapsulated in a $3 \mathrm{D}$ sodium alginate culture system to maintain a phenotype more typical of that seen for nucleus pulposus cells in vivo than when grown in monolayer (Horner et al., 2002). We show that the growth and survival of bovine NP cells within this system is regulated by these factors in this in vitro model, which has given rise to cell phenotypes seen in pathological discs, including cell proliferation and clustering, cell senescence and cell death as seen in pathological IVD.

\section{Materials and Methods}

\section{Intervertebral disc cells}

IVD cells were isolated from the nucleus pulposus (NP) of adult bovine caudal IVD by enzymatic digestion and expanded in monolayer culture in Dulbecco's Modified Eagles Medium (DMEM/F12; Invitrogen, Paisley, UK; catalogue number: $31330-58)$, containing $3.15 \mathrm{~g} / \mathrm{L}$ (17.5 mM) glucose and sodium pyruvate $(55 \mathrm{mg} / \mathrm{L})$ supplemented with $10 \%(\mathrm{v} / \mathrm{v})$ foetal calf serum (FCS), $100 \mu \mathrm{U} / \mathrm{mL}$ penicillin and $100 \mu \mathrm{g} / \mathrm{mL}$ streptomycin, as described previously (Johnson et al., 2008). At passage II, NP cells were encapsulated into sodium alginate (ISP Keltone) beads at final cell densities of $1.25 \times 10^{5}$, $2.5 \times 10^{5}, 5 \times 10^{5}$, and $1 \times 10^{6}$ cells $/ \mathrm{mL}$ with a final alginate concentration of $1.2 \%(\mathrm{w} / \mathrm{v})$ and polymerised in $100 \mathrm{mM}$ $\mathrm{CaCl}_{2}$. Culture conditions using DMEM F12 medium containing $3.15 \mathrm{~g} / \mathrm{L}$ glucose and $55 \mathrm{mg} / \mathrm{L}$ sodium pyruvate supplemented with $10 \% \mathrm{FCS}, 100 \mu \mathrm{U} / \mathrm{mL}$ penicillin and $100 \mu \mathrm{g} / \mathrm{mL}$ streptomycin were designated as 'standard' cell culture conditions. NP cells were also cultured with varying concentrations of FCS $(0,10$ and $20 \%)$ or in DMEM/F12 without glucose or sodium pyruvate (Catalogue number 11966025). All culture media were at $\mathrm{pH}$ 6.9-7.1 and $312-321 \mathrm{mOsm} / \mathrm{kg}$ water. Cells were fed at 48 hourly intervals after the initial seeding and maintained at $37{ }^{\circ} \mathrm{C}$ with $5 \% \mathrm{CO}_{2}$ and atmospheric oxygen in all experiments before harvesting on days 0,4 and 8 . (All reagents were from Invitrogen unless otherwise stated). Alginate beads were depolymerised with $10 \mathrm{mM}$ EDTA-PBS and cytospin preparations (using 1 alginate bead each time) were made by spinning at $500 \mathrm{rpm}$ for $3 \mathrm{~min}$ (Shandon Cytospin 2, Thermo Scientific Shandon, Loughborough, UK).

\section{Cell proliferation, viability and apoptosis}

Cell viability within alginate beads was assessed by 'live/ dead' scoring (LIVE/DEAD, Invitrogen), where live cells that maintained non-specific esterase activity cleave calcein-AM to produce green fluorescence, but dead cells that have compromised membranes are permissive to penetration of ethidium homodimer, which binds to nuclear DNA and fluoresces red. Cytospins were stained with haematoxylin and eosin or diamidino-2-phenylindole (DAPI) and cells counted as single cells, paired cells and cell clusters (defined as 3 or more cells; more than 200 cells were counted per sample). Apoptosis was identified morphologically in DAPI-stained cytospins via pyknosis and karyorhexis (nuclear fragmentation), scoring the frequency in 200 or more cells. The proliferation status of cells was examined by immunocytochemistry for the proliferation-associated Ki67 antigen. For this, cytospins were fixed in $10 \%$ formalin for $10 \mathrm{~min}$, washed with phosphate buffered saline (PBS) and subjected to antigen retrieval overnight at $60{ }^{\circ} \mathrm{C}$ in $50 \mathrm{mM}$ Tris buffer, $\mathrm{pH} 8$, before incubating with 1:50 v/v monoclonal antibody specific for Ki67 in PBS (Novocastra, Newcastle upon Tyne, UK). Immunoreactivity was detected using a commercial kit (Vectastain ABC Elite, VectorLabs Ltd., Peterborough, UK) combined with 3,3'-diaminobenzidine (DAB) staining (Vector Labs). Isotype-matched irrelevant antibodies (Dako, Ely, UK) were used in place of the primary antibody as a negative control. The proportion of Ki67 immunopositive cells was determined by counting more than 200 cells per sample.

\section{Cell senescence}

Senescent cells were identified by their production of senescence associated- $\beta$-galactosidase (SA- $\beta$-Gal), which is demonstrated by histochemical staining with the substrate 5-bromo-4-chloro-3-indolyl B-Dgalactopyranoside titrated to $\mathrm{pH} 6.0$ (in comparison to lysosomal $\beta$ galactosidase at $\mathrm{pH}$ 4.0) (Dimri et al., 1995). The proportion of SA- $\beta$-Gal positive cells was determined by counting at least 200 cells per sample.

\section{Filamentous actin staining with phalloidin-FITC}

Cytospins were fixed with $10 \%$ formalin for $10 \mathrm{~min}$ and washed with PBS, before incubating with phalloidin-FITC (Molecular Probes/Invitrogen, diluted 1:100 (v/v) in PBS) at room temperature for $30 \mathrm{~min}$. Slides were then washed with PBS and mounted in Vectamount containing DAPI to counterstain cell nuclei.

\section{Cell labelling with cell linker, PKH26}

Cytospin preparations were air dried and washed with distilled water, before staining with the red fluorescent cell linker, PKH26 (Sigma-Aldrich, Gillingham, UK); the dye was diluted 1:200 v/v in buffer, according to the manufacturer's instructions and used at room temperature for $15 \mathrm{~min}$. Slides were then washed with PBS and mounted in Vectamount containing DAPI to counterstain cell nuclei.

\section{Microscopy and image capture}

NP cells were viewed, either in situ within alginate bead cultures or in the cytospins using phase contrast and fluorescence microscopy (Nikon Eclipse TS100, Nikon, Kingston-upon-Thames, UK). Digitised images were captured with a Hamamatsu (C4742-95) or Nikon (Coolpix) digital camera and examined using IP Lab software (Version 3.6, Nikon).

\section{Statistical analysis}

Each experiment was carried out in triplicate, with each set of NP cell cultures having been established from tails of 3 different cows (the NP cells being isolated and pooled from 5 discs for each cow). Differences between 2 groups 
a)
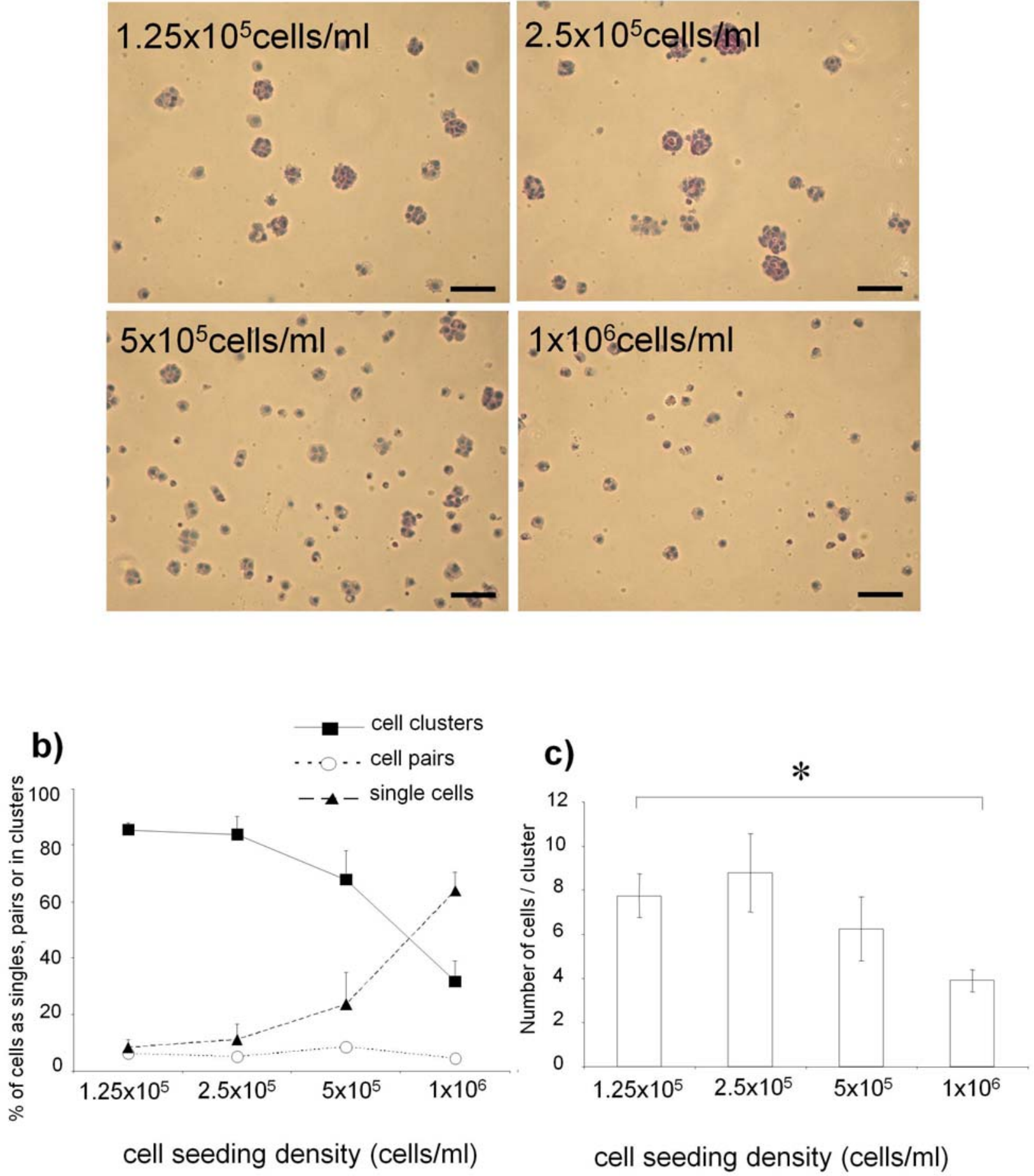

Fig. 1. (a) Representative wide field images showing cell distribution over a range of cell seeding densities $\left(1.25 \times 10^{5}-1 \times 10^{6}\right.$ cells $\left./ \mathrm{mL}\right)$ after $8 \mathrm{~d}$ in culture in alginate beads in standard culture conditions. Cells were stained with haematoxylin and eosin. Scale bars represent $40 \mu \mathrm{m}$. (b) Graph shows the mean percentages of cells in clusters, pairs or single cells in alginate beads seeded at different cell densities and cultured in standard conditions ( \pm SD). (c) The average number of cells per cluster also varied with seeding density mean \pm SD), (* denotes significantly more cells/cluster $(p<0.05)$ at $1.25 \times 10^{5}$ compared to $1 \times 10^{6}$ cells $\left./ \mathrm{mL}\right)$. 


\section{a) $1.25 \times 10^{5}$ cells $/ \mathrm{ml}$ \\ b) $1 \times 10^{6} \mathrm{cells} / \mathrm{ml}$}

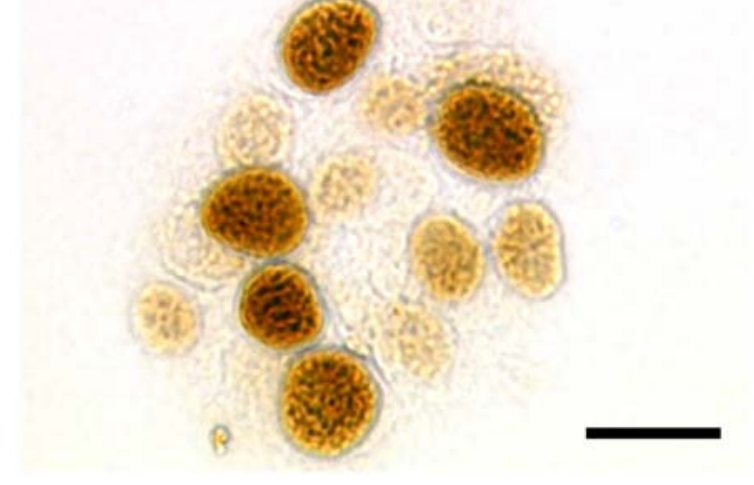

c)

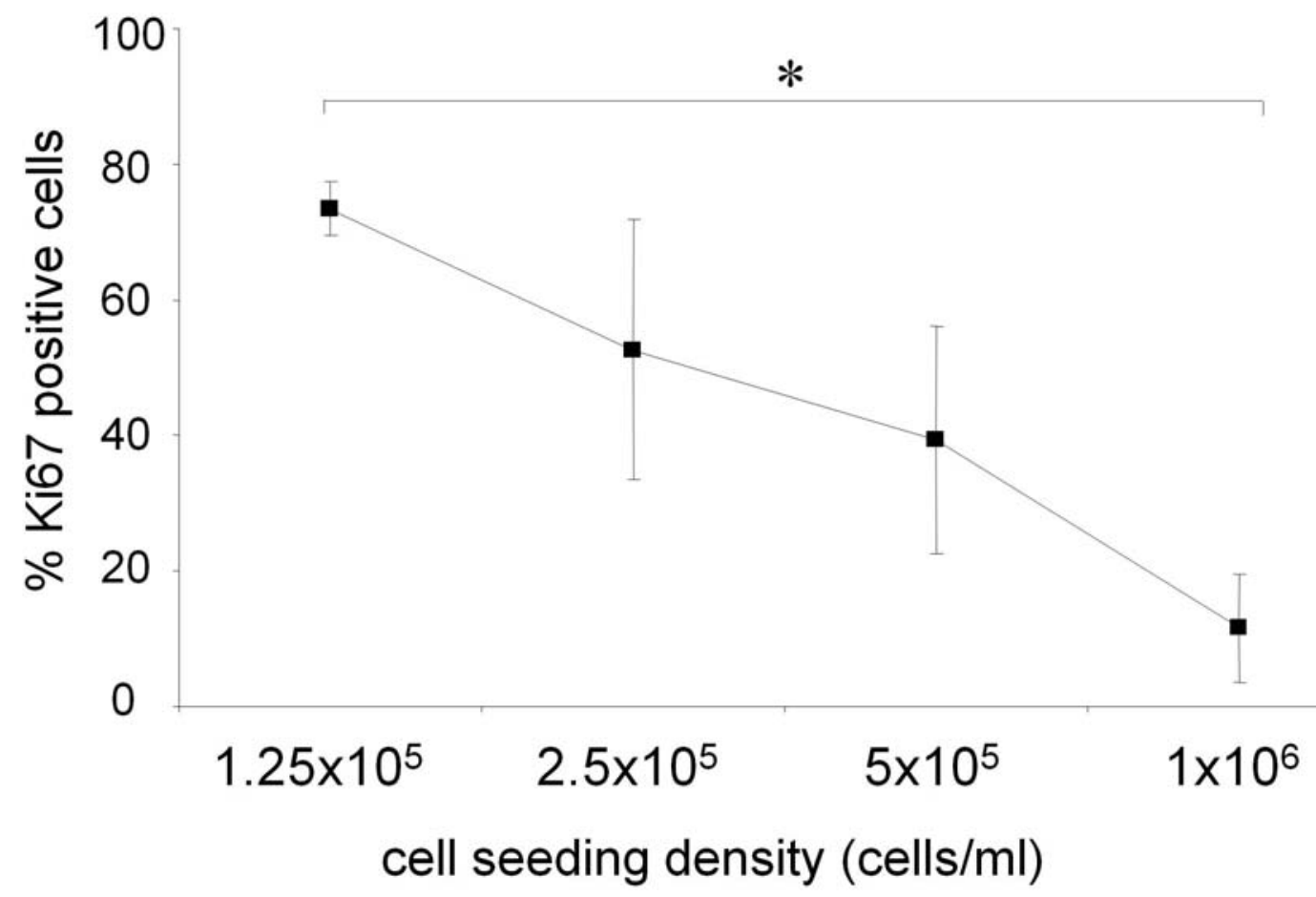

Fig 2. Ki67 immunopositivity of cells grown in alginate beads was greatest in cells seeded at the lower density (a) compared to high cell seeding density (b) (arrows indicate negatively stained nuclei). Scale bars represent $10 \mu \mathrm{m}$. (c) Percentage of Ki67 positive cells cultured in standard conditions after $8 \mathrm{~d} \pm \mathrm{SD}$ of the mean. (* denotes significantly more cell proliferation $(p<0.05)$ with cells seeded at $1.25 \times 10^{5}$ cells $/ \mathrm{mL}$ compared to $1.0 \times 10^{6}$ cells $\left./ \mathrm{mL}\right)$.

were evaluated with the Mann-Whitney $U$ test or for more than 2 groups, with the Kruskal-Wallis ANOVA, using SPSSv15 (IBM/SPSS, Portsmouth, UK) or Analyse-It software. All data are expressed as means \pm standard deviation of the mean (SD). Significant differences were accepted at $p<0.05$.

\section{Results}

NP cell proliferation and cluster formation were inversely related to cell density

NP cells that had been encapsulated in alginate beads were evenly distributed as single cells throughout the alginate (day 0 cultures). In contrast, after 4 and $8 \mathrm{~d}$ in standard culture conditions in alginate beads, NP cells formed cell clusters, visible both in situ within the alginate and when harvested as cytospins. The formation of these NP cell clusters was dependent on the seeding density, such that at densities of $1.25 \times 10^{5}$ and $2.5 \times 10^{5}$ cells $/ \mathrm{mL}$, the majority of NP cells were in cell clusters, but there were fewer clusters in cultures seeded at $5 \times 10^{5}$ cells $/ \mathrm{mL}$. At a seeding density of $10^{6}$ cells $/ \mathrm{mL}$, most NP cells remained single, even after $8 \mathrm{~d}$ in culture in standard culture conditions (Fig. 1a,b). The proportion of NP cells comprising clusters at day 8 was significantly less $(p \leq 0.05)$ at $10^{6}$ cells $/ \mathrm{mL}$ than that at $1.25 \times 10^{5}$ cells $/ \mathrm{mL}$. In contrast, the proportion of single NP cells was significantly greater $(p \leq 0.05)$ at a 
a)

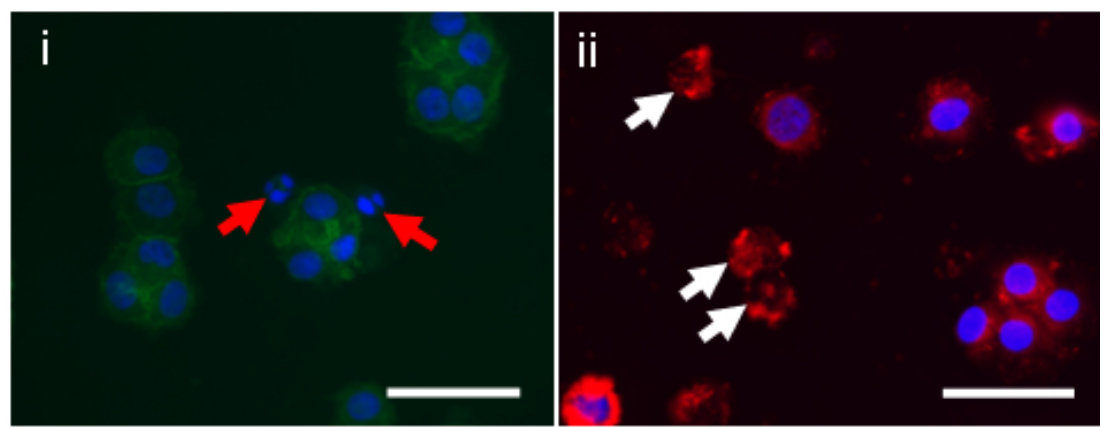

b)

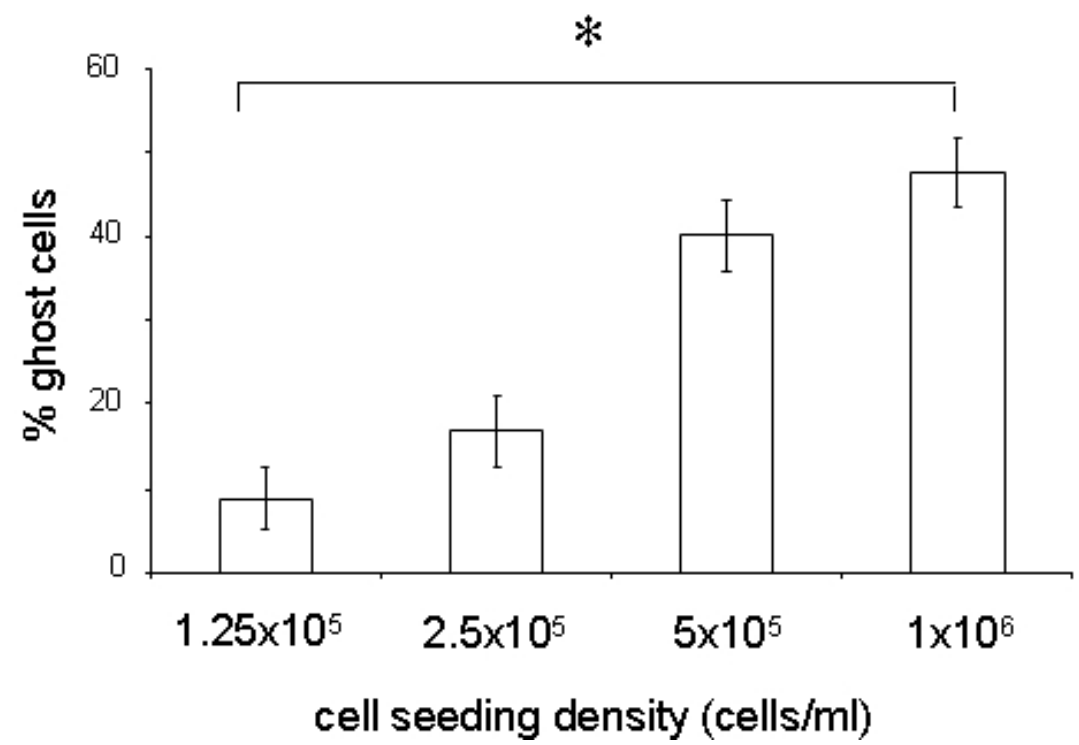

Fig 3. (a) Images of apoptotic and "ghost" cells. (i) Apoptotic cells were identified morphologically with DAPI staining (blue) showing blebbed nuclei or karyorhexis (red arrows); F-actin staining (green) was greatly reduced in these cells. (ii) Ghost cells, consisting of cell bodies lacking DAPI-stained nuclei, were positive for the cell tracker, PKH26 red (white arrows). Scale bars represent $50 \mu \mathrm{m}$. (b) Percentage of ghost cells (negative for DAPI staining) in cells cultured in alginate beads at standard conditions (i.e., in $10 \% \mathrm{FCS}, 17.5 \mathrm{mM}$ glucose and $55 \mathrm{mg} / \mathrm{L}$ sodium pyruvate) for $8 \mathrm{~d} \pm \mathrm{SD}\left(*\right.$ denotes significantly more ghost cells $(p<0.05)$ in cells seeded at $1.0 \times 10^{6}$ cells/ $\mathrm{mL}$ compared to $1.25 \times 10^{5}$ cells $/ \mathrm{mL}$ ).

cell seeding density of $10^{6}$ cells $/ \mathrm{mL}$ than that at $1.25 \times 10^{5}$ cells $/ \mathrm{mL}$ in standard culture conditions. The number of cells in one cluster was also related to the seeding density (not significantly at day $4(p=0.74)$, but the relationship was significant at day $8(p=0.04))$. Hence there were more NP cells per cluster, i.e. the clusters were bigger, at a cell seeding density of $1.25 \times 10^{5}$ cells $/ \mathrm{mL}$ ( $8 \pm 1$ cells/cluster $)$ than at a cell seeding density of $10^{6}$ cells $/ \mathrm{mL}$ in standard culture conditions ( $4 \pm 1$ cells/cluster; Fig. $1 \mathrm{c})$.

Immunopositivity for the proliferation-associated Ki67 antigen was most frequently seen in NP cells within clusters in cultures seeded at $1.25 \times 10^{5}$ cells $/ \mathrm{mL}$, where $>70 \%$ of the NP cells were Ki67-immunopositive in standard culture conditions (Fig. 2). Conversely, fewer NP cells seeded at the higher cell density of $10^{6}$ cells $/ \mathrm{mL}$ were Ki67-positive (with $<10 \%$ cells staining positive for Ki67 antigen). There was an inverse significant relationship between Ki67 immunopositivity and seeding density $(p=0.02$ after $8 \mathrm{~d}$ in standard culture conditions in alginate beads; Fig. 2c).

\section{NP cell death and "ghost cells"}

The percentage of viable cells as assessed by Live/Dead staining demonstrated $90 \%$ or more viability (staining green) for all seeding densities, with more dead cells in clusters than single cells ( $9 \%$ and $1 \%$, respectively, in standard culture conditions) for all seeding densities except 
a)

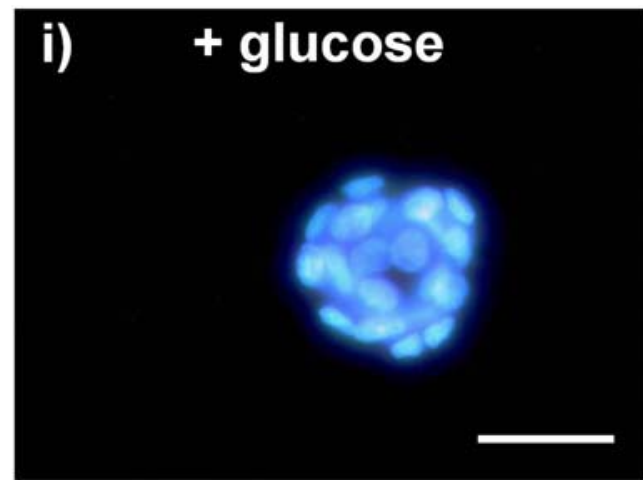

7i)

$10 \%$ FCS
$20 \%$ FCS

b)

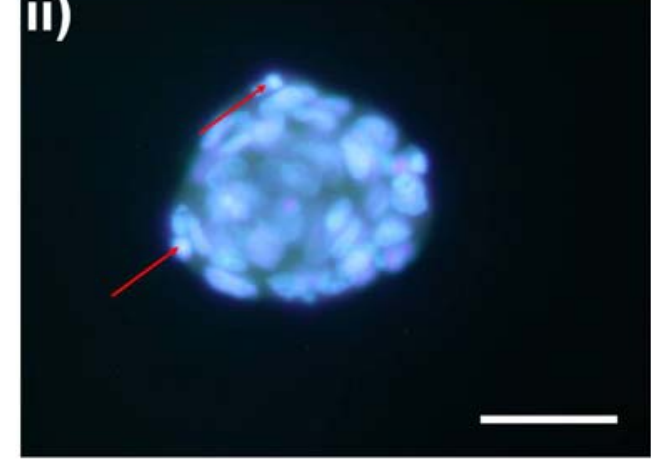

+ glucose

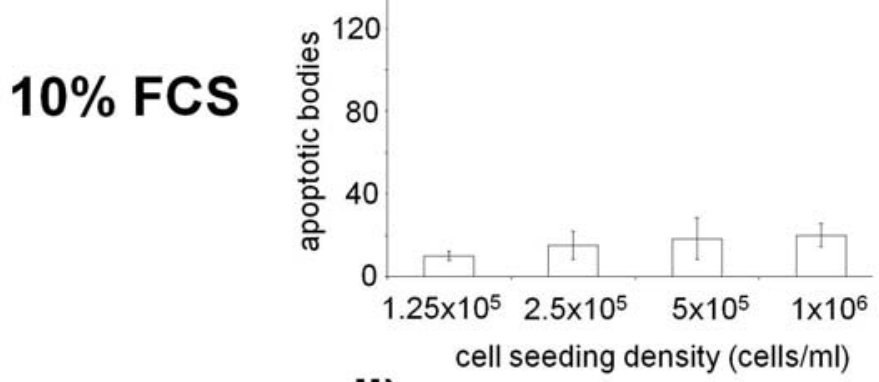

ii)

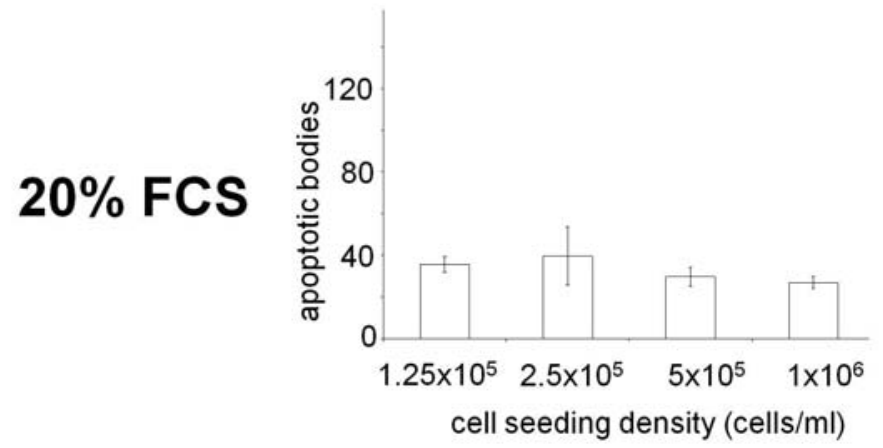

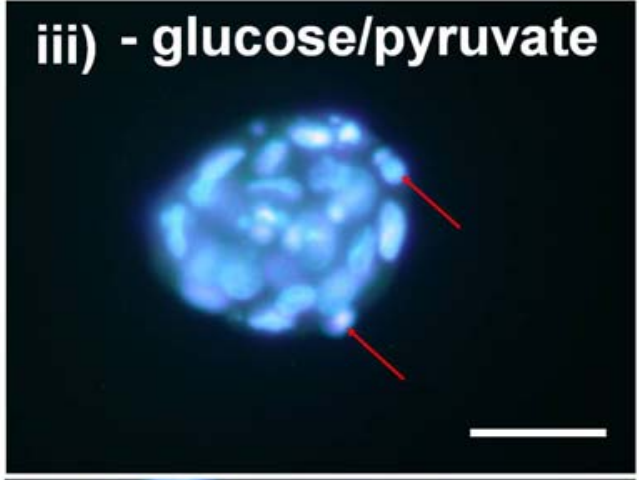

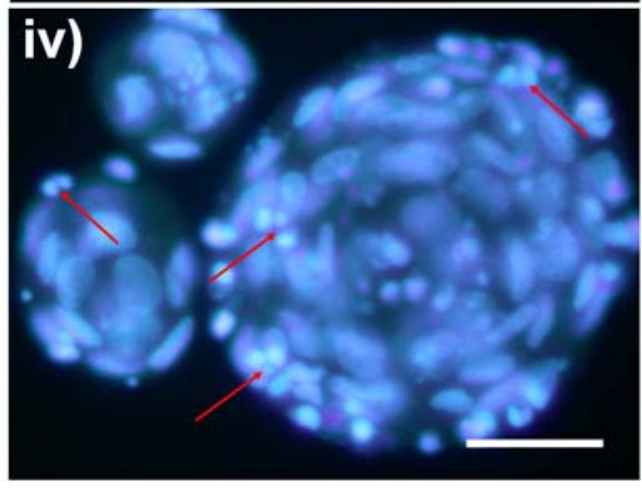

iii) - glucose/pyruvate *
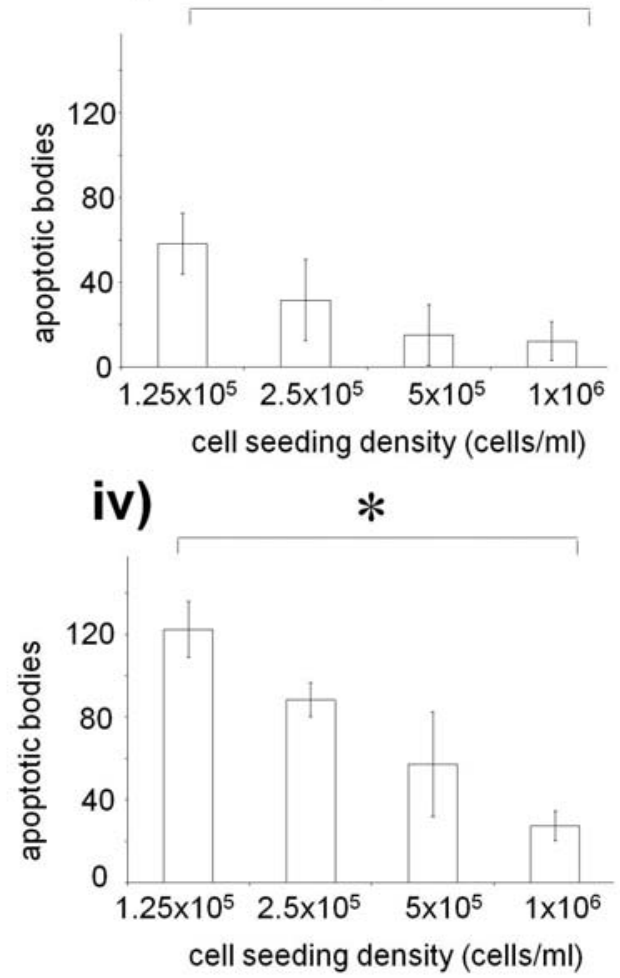

Fig 4. (a) Representative images of DAPI-stained NP cells seeded into alginate beads at $1.25 \times 10^{5}$ cells $/ \mathrm{mL}$ forming clusters in (i) $10 \% \mathrm{FCS}$, (ii) $20 \% \mathrm{FCS}$, (iii) $10 \% \mathrm{FCS}$, without glucose or pyruvate and iv) $20 \%$ FCS without glucose or pyruvate. Red arrows show apoptotic nuclei. Scale bars represent $50 \mu \mathrm{m}$. (b) Graphs showing the frequency ( \pm SD) of apoptotic cells per 200 cells when cultured in (i) $10 \%$ FCS, (ii) $20 \%$ FCS, (iii) $10 \%$ FCS without glucose or (iv) $20 \%$ FCS without glucose (* denotes significantly more apoptotic cells in 'no glucose' conditions $(p<0.05)$ at day 8 in cells seeded at $1.25 \times 10^{5}$ cells $/ \mathrm{mL}$ compared to $1.0 \times 10^{6}$ cells $\left./ \mathrm{mL}\right)$. 


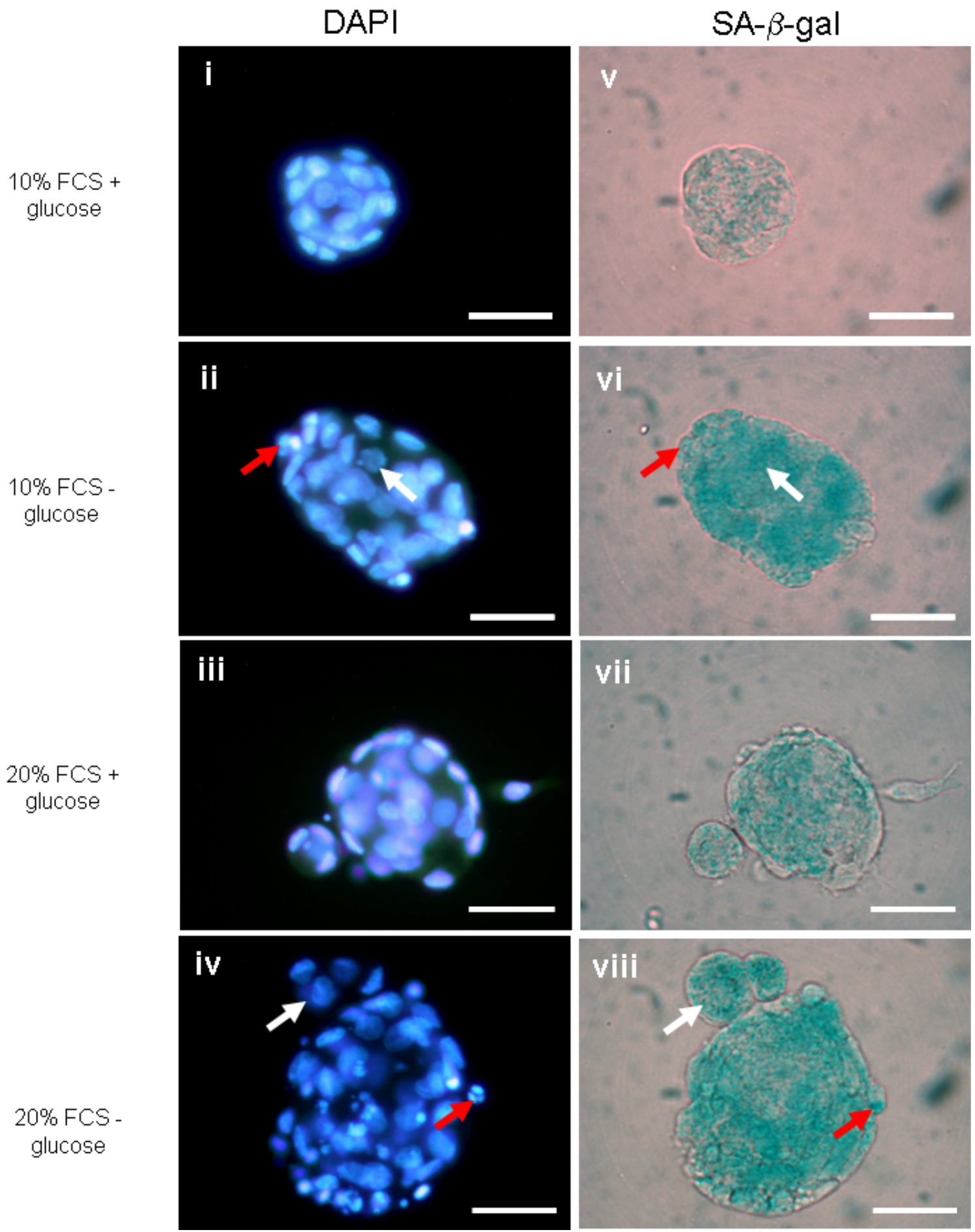

Fig. 5. Representative images of (i-iv) DAPI-stained cell clusters formed by cells seeded at $1.25 \times 10^{5}$ cells $/ \mathrm{mL}$ and (v-viii) SA- $\beta$-gal staining within the same cells showing senescence, after $8 \mathrm{~d}$ culture in alginate beads. (Red arrows show nuclear morphology typical of apoptotic cells in DAPI-stained images and white arrows indicate normal, viable cells.). Scale bars represent $50 \mu \mathrm{m}$.

$10^{6}$. These results were substantiated by the counts of cells with apoptotic morphology (demonstrated by DAPI). In addition to these 'live' and 'dead' cells we also noted the presence of cell-sized entities, which did not contain DNA (as revealed by DAPI staining) but nonetheless labelled with the membrane-binding cell tracker and F-actin (Fig. 3a). The presence of these "ghost" cells was also significantly related to cell density, with most observed at the greatest cell density when cells were grown in standard culture conditions ( $p=0.03$ at day 8; Fig. 3b).

\section{The effects of serum and glucose levels were cell density dependent}

In alginate cultures maintained in $20 \% \mathrm{FCS}$, the NP cell clusters that formed at low seeding densities were larger than those clusters that had formed in $10 \%$ FCS. There 
was also an apparent increase in cluster size when cultured in medium that did not contain any glucose or pyruvate, whether it was supplemented with $10 \%$ or $20 \%$ FCS. However, although the size of clusters in glucose-free medium was markedly larger, the number of apoptotic bodies seen also increased, though this was not statistically significant (Fig. 4a,b). The frequency of apoptosis and the size of cell clusters were greatest when cells were cultured at $1.25 \times 10^{5}$ cells $/ \mathrm{mL}$ in medium, containing $20 \% \mathrm{FCS}$ with no glucose or pyruvate. An increased cell seeding density was associated with decreased cell viability at day 8 in cultures maintained in $10 \% \mathrm{FCS}$ and in the presence of glucose. However, this inverse relationship was reversed to become a positive association between seeding cell density and cell viability in the absence of glucose, both in $10 \%$ and $20 \%$ FCS.

\section{Cell senescence}

Senescent NP cells, as demonstrated by SA- $\beta$-galactosidase staining, were commonly seen within cell clusters of cultures in both $10 \%$ and $20 \%$ serum with glucose. However, in those cultures that were maintained without glucose or pyruvate, the NP cells in clusters showed even more intense SA- $\beta$-Gal positive staining (Fig. 5). This staining appeared equally intense in NP cells with normal and apoptotic morphologies.

\section{Discussion}

An increase in the number of non-viable cells present in the human intervertebral disc has been associated with both ageing and disc degeneration (Boos et al., 2002). Reduced availability of nutrients is suggested to occur through an age-related sclerosis of the cartilaginous endplates and is thought to play an important role in this pathology (Nachemson et al., 1970; Boos et al., 2002; Bibby and Urban, 2003; Grunhagen et al., 2006;). In vitro experimentation has lent support to such a hypothesis, where reducing levels of glucose has been found to decrease cell viability significantly (Bibby and Urban, 2003) whilst lowering serum levels increased cell proliferation and senescence in cultured IVD cells (Johnson et al., 2008). It has been suggested that modified nutrient and growth factor availability to disc cells in vivo may influence cell behaviour. Indeed, analysis of surgically removed human disc tissue has shown cell clusters (Ford et al., 2002) composed of proliferating (Johnson et al., 2001), senescent (Roberts et al., 2006b) and apoptotic disc cells (Park et al., 2001a).

The aim of this study was to examine further the influence of nutrient supply and the availability of blood borne growth and survival factors on IVD cells in a defined 3 dimensional system that maintains their in vivo phenotype (Horner et al., 2002). We have also shown that NP cells form clusters in this alginate culture system, particularly when they are maintained in the absence of glucose or pyruvate (Johnson et al., 2008), possibly mimicking pathological processes that occur in IVD degeneration. In that previous study (Johnson et al., 2001) a constant density of 1 million IVD cells $/ \mathrm{mL}$ was used throughout the experimentation. In the present study, we have demonstrated that reducing the number of IVD cells below a density of $10^{6} / \mathrm{mL}$, such as might occur in IVD degeneration, resulted in increased NP cell proliferation (as delineated both by Ki67 immunopositivity (Johnson et al., 2001) and the lack of any evidence of cell migration or changes in cell morphology over time that would be associated with such migration, (e.g. the presence of cell processes or actual movement under video microscopy). Hence, we found that increased NP cell proliferation and cell cluster formation was inversely correlated with cell seeding density.

It may be that levels of both nutritive and growth or survival factors that were available to the NP cells in this culture system directly influenced their proliferative capacity. There are numerous factors present in serum that have been reported to enhance NP cell proliferation and survival, including platelet-derived growth factor (PDGF), transforming growth factor- $\beta$ (TGF- $\beta$ ), insulin-like growth factor (IGF) and fibroblast growth factor (FGF) (Gruber et al., 2000; Pratsinis and Kletsas, 2007). This perhaps explains the increased proliferation and larger clusters found with $20 \%$ FCS compared to those with $10 \%$ FCS. Indeed, increasing the concentration of FCS has been shown to increase proliferation rates of other cell types in culture, which has been attributed to growth factors within it (Naseer et al., 2009) and the addition of FGF to wounded cartilage stimulated chondrocytes to proliferate and form clusters (Khan et al., 2010).

However, in addition to evidence of cell proliferation in these culture conditions we also found evidence of cell death. Apoptotic cells, as identified by the presence of karyorhexis, were most frequent in standard culture conditions in clusters formed in cultures seeded at the highest density of $1 \times 10^{6}$ cells $/ \mathrm{mL}$. It could be considered contradictory that apoptotic NP cells were frequently observed within clusters of cells that arose in cultures with an initial low seeding cell density, whilst apoptotic cells were also observed in cultures established at high seeding cell density. However, these observations may reflect that the level of survival factors was adequate at low seeding cell densities, until these cultures proliferated to exceed the number of cells that could be supported. The cultures with high seeding densities may reach this level at different time points. Hence, each situation might change as cell proliferation leads to the formation of cell clusters over time, such that the levels of growth/survival factors are locally limited and hence insufficient to prevent apoptosis.

Unexpectedly, however, another morphology was also found in the present study, that of cells with an intact cytoplasmic membrane but no apparent intact chromatin, or certainly none which was capable of reacting with ethidium bromide or DAPI. We have termed these "ghost cells" similar to those described in other populations of cells, for example, in odontomas, where this term describes anucleate cells with homogenous cytoplasm (Kim et al., 2000). In these tumours, ghost cells can form large clusters and may be related to a malfunctioning Wnt pathway (Tanaka et al., 2007) and/or apoptosis (Kim et al., 2000). Certainly ghost cells were also observed in the present study to occur at significantly higher numbers in beads 
seeded at $1 \times 10^{6}$ cells $/ \mathrm{mL}$ compared to those seeded at the lowest density. The formation of cells with this morphology in the present study could have relevance to disc pathology, since areas have been identified in degenerate discs resembling "cell ghosts" where remnants of cells appear to be replaced by extracellular matrix (Roberts, 2001). It is widely accepted that cells in general can die by different cellular pathways and mechanisms, and for many years disc cells have been shown to be able to die via necrosis or apoptosis (Trout et al., 1982; Lotz and Chin, 2000). However, additional forms of cell death have been reported in other cell types including oncosis, autophagy or anoikis (Kroemer et al., 2005). Indeed, recently disc cells with a different morphology, 'balloon cells', have been described in human discs, apparently associated with cell death (Sitte et al., 2010). This suggests that we have perhaps had a more simplistic impression of the types of cell death that disc cells can undergo than is really the case.

We have previously shown that glucose/pyruvate levels can influence disc cell proliferation, both in monolayer and 3-D alginate bead culture, with them proliferating more rapidly in the absence of glucose or pyruvate than when present at $17.5 \mathrm{mM}$ (Johnson et al., 2001). In reality the 'absence of glucose' is likely to have been hypoglycaemic conditions (approximately 1-2 $\mathrm{mM}$ ) rather than a complete absence, due to the addition of FCS in the medium which contains glucose. Elevated levels of glucose have been seen to inhibit proliferation of other cell types, e.g. endothelial cells (Chen et al., 2007) or renal proximal tubule cells (25 mM glucose) (Park et al., 2001b). This appears to be effected via oxidative stress pathways, being dependent on ERK1/2 and PKC. Hence the association with proliferation rates and levels of senescence seen in the present study is perhaps not surprising. However, survival of disc cells, as for other cell types such as heart muscle cells (Ghatnekar et al., 2004) has been shown to be dependent on a minimum amount of glucose being present. Bibby and Urban (2004) demonstrated that $0.5 \mathrm{mM}$ glucose is necessary for NP cell survival at $24 \mathrm{~h}$ in alginate culture, with cell death occurring particularly fast if grown in $21 \%$ oxygen (rather than $0 \%$ ) or in acidic conditions. This and other studies show how important it is to study combined environmental factors which are more likely to reflect the situation in vivo than simply altering one variable alone, as has been demonstrated by other workers (NeidlingerWilke et al., 2009). Our study has, however, focussed on the relationships between cell density and levels of serum and glucose only as far as cell growth and survival is concerned; clearly the capacity of the NP cells to function is of major importance. Further experimentation would be required to address ECM synthesis that is obviously very important to the functioning of the disc, particularly with respect to its mechanical properties.

The cells within the healthy intervertebral disc are normally exposed to relatively low levels of serum compared to other locations within the body. It is possible that the cells may adapt to functioning in this environment. In disorders leading to disc degeneration, for example, via calcification of the endplate (Benneker et al., 2005) or in disc herniation when the disc's structural integrity fails, cells may become exposed to different levels of nutrients (Urban et al., 2004) or serum and its associated growth factors. In the present study, we have shown that nutrient availability in the alginate cultures directly influences cell proliferation and cluster formation, associated senescence and apoptosis, almost to the point of suggesting that NP cells sense their ideal cell density and start to proliferate when there are few cells, or go into apoptosis if there are too many. The exposure of NP cells to additional serum (from $10 \%$ to $20 \%$ serum) promoted cell proliferation and formation of large cell clusters containing apoptotic cell nuclei. Lower levels of glucose/pyruvate in the culture medium, with either $10 \%$ or $20 \%$ serum, also had profound effects on the cellular behaviour. Hence, cells deprived of glucose/pyruvate proliferated to produce larger cell colonies, but with many apoptotic and senescent cells. (The only assessment of senescence used in this study was SA- $\beta-$ Gal positivity, which has its limitations as a technique and can fail to differentiate between cells which are senescent from those in crisis (Cristofalo, 2005)). In addition to this, senescence in a cell does not necessarily render the cell non-functional; it remains viable but may have an altered metabolism (Le Maitre et al., 2007; Gruber et al., 2010). This demonstration in vitro that the amount of serum and glucose which is available to disc cells directly influences their ability to both proliferate and survive within alginate beads could explain the presence of proliferating (Johnson et al., 2001), senescent (Roberts et al., 2006a), stressed (Sharp et al., 2009) and/or dying cells (Roberts et al., 2006b) in clusters in vivo in human intervertebral discs.

The influence of seeding densities in culture has been examined in other cell types, particularly with relevance to tissue engineering. The results are quite varied, however, with the cell number or density of mesenchymal stem cells being reported for example as both 'affecting the regenerative capability' (Serigano et al., 2010) and also 'not critical' (Neuhuber et al., 2008). Increasing the seeding density of articular chondrocytes is reported as both affecting cell behaviour (Khoshfetrat et al., 2009), improving chondrogenesis (Francioli et al., 2010), and as with intervertebral disc cells, leading to increased GAG and collagen production in alginate beads, but also subsequent apoptosis (Kobayashi et al., 2008). Hence, in terms of cell therapy and tissue engineering of the disc, it would appear that there is likely a compromise between increasing cell number and the health status of individual cells, i.e. the simple assumption that more cells is better may not be ideal if cell expansion promotes aberrant cell behaviour and/or cell death. There is also the additional possibility that the cells may adjust themselves to the optimal population for the location by exerting autogenic control, in which case the number of cells to be introduced as cell therapy may not be critical.

\section{Conclusion}

This study demonstrates that the optimal cell density for NP cells in alginate culture systems for tissue engineering purposes, or in the context of cell transplantation therapies, clearly depends on levels of serum and glucose 
supplementation, at least in terms of cell growth and viability. As such it could have implications for both the understanding of in vivo degenerative disc pathology and tissue engineering methods. The proliferative capacity of disc cells may be influenced by the nutrient and/or growth factor availability in vivo in the disc, similar to that seen here in 3-D culture of NP cells in alginate. Cells of the intervertebral disc could experience changes in nutrient supply either in degeneration with increased calcification of the vertebral endplate (leading to decreased levels) or when there is herniation of the disc, when cells may be exposed to greater levels of glucose or serum factors which may promote localised NP cell proliferation, cellular apoptosis and senescence. We have shown that all of these biological responses occur in vitro and can be modified by glucose/pyruvate and serum concentrations. The exposure of NP cells to additional serum (from $10 \%$ to $20 \%$ serum) promoted cell proliferation and formation of large cell clusters containing apoptotic cell nuclei. Lower levels of glucose in the culture medium, with either $10 \%$ or $20 \%$ serum, also had profound effects on the cellular behaviour. In addition, we describe the formation of "ghost" cells, a novel morphology for the intervertebral disc. The use of NP cells in an alginate culture model hence provides further understanding of how cell biology could influence disc degeneration and also provide insight into how these processes may be manipulated to promote disc regeneration. Furthermore, this study has shown for the first time that the seeding density of NP cells may be critical to their intrinsic ability to survive and proliferate. Indeed, this study provides evidence for the existence of a possible autogenic control of NP cell number in vivo, which has direct relevance to potential cell therapy or tissue engineering situations.

\section{Acknowledgements}

We are grateful to Mr Philip Jones for some technical assistance. The work was funded by the Biotechnology and Biological Sciences Research Council that supported S. Stephan, W.E.B. Johnson and P. Jones. S. Roberts was supported by funding from the EC's 7th Framework Programme (FP7, 2007-2013) under grant agreement no. HEALTH-F2-2008-201626 (Genodisc).

\section{References}

Adams MA, Roughley PJ (2006) What is intervertebral disc degeneration, and what causes it? Spine 31: 21512161.

Benneker LM, Heini PF, Alini M, Anderson SE, Ito $\mathrm{K}$ (2005) Vertebral endplate marrow contact channel occlusions and intervertebral disc degeneration. Spine 30: 167-173.

Bernick S, Caillet R (1982) vertebral end-plate changes with aging of human vertebrae. Spine 7: 97-102.

Bibby SRS, Urban JPG (2004) Effect of nutrient deprivation on the viability of intervertebral disc cells. Eur Spine J 13: 695-701.
Boos N, Weissbach S, Rohrbach H, Weiler C, Spratt KF, Nerlich AG (2002) Classification of age-related changes in lumbar intervertebral discs. Spine 27: 2631-2644

Chen Y-H, Guh J-Y, Chuang T-D, Chen H-C, Chiou S-J, Huang S, Yang Y-L, Chuang L-Y (2007) High glucose decreases endothelial cell proliferation via the extracellular signal regulated kinase/p15 $5^{\mathrm{INK} 4 \mathrm{~b}}$ pathway. Biochem Biophys 465: 164-171.

Cristofalo VJ (2005) SA $\beta$ Gal staining: Biomarker or delusion. Exp Gerontol 40: 826-838.

Dimri GP, Lee X, Basile G, Acosta M, Scott G, Roskelley C, Medrano EE, Linskens M, Rubelj I, PereiraSmith O, Peacocke M, Campisi J (1995) A biomarker that identifies senescent human cells in culture and in aging skin in vivo. Proc Natl Acad Sci USA 92: 9363-9367.

Ford JL, Jones P, Downes S (2002) Cellularity of human annulus tissue: an investigation into the cellularity of tissue of different pathologies Histopathol 41: 531-537.

Francioli SE, Candrian C, Martin K, Heberer M, Martin I, Barbero A (2010) Effect of three-dimensional expansion and cell seeding density on the cartilage-forming capacity of human articular chondrocytes in type II collagen sponges. J Biomed Mater Res A 95: 924-931.

Ghatnekar GS, Barnes JA, Dow JL, Smoak IW (2004) Hypoglycemia induced changes in cell death and cell proliferation in the organogenesis stage embryonic mouse heart. Birth Defects Res A Clin Mol Teratol 70: 121-131.

Gruber HE, Hanley EN (1998) Analysis of aging and degeneration of the human intervertebral disc: comparison of surgical specimens with normal controls. Spine 23: 751757.

Gruber HE, Norton HJ, Hanley EN (2000)Anti-apoptotic effects of IGF-1 and PDGF on human intervertebral disc cells in vitro. Spine 25: 2153-2157.

Gruber HE, Hoelscher GL, Ingram JA, Zinchenko N, Hanley Jr EN (2010) Senescent vs. non-senescent cells in the human annulus in vivo: Cell harvest with laser capture microdissection and gene expression studies with microarray analysis. BMC Biotechnol 10: 1-10.

Grunhagen T, Wilde G, Soukane DM, Shirazi-Adl SA, Urban JP (2006) Nutrient supply and intervertebral disc metabolism. J Bone Joint Surg [Am] 88 Suppl 2: 30-35.

Holm S, Maroudas A, Urban JPG, Selstam G, Nachemson A (1981) Nutrition of the intervertebral disc: solute transport and metabolism. Conn Tiss Res 8: 101-119.

Horner HA, Roberts S, Bielby RC, Menage J, Evans H, Urban JPG (2002) Cells from different regions of the intervertebral disc. Effect of culture system on matrix expression and cell phenotype. Spine 27: 1018-1028.

Ishihara H, Warensjo K, Roberts S, Urban JPG (1997) Proteoglycan synthesis in the intervertebral disk nucleus: the role of extracellular osmolality. Am J Physiol 212: C1499-C1506.

Johnson WEB, Eisenstein SM, Roberts S (2001) Cell cluster formation in degenerate lumbar intervertebral disc is associated with increased disc cell proliferation. Conn Tiss Res 42: 197-207.

Johnson WEB, Stephan S, Roberts S (2008) The influence of serum, glucose and oxygen on intervertebral disc cell growth in vitro: implications for degenerative disc disease. Arth Res Ther 10: R46. 
Kauppila LI (1995) Ingrowth of blood vessels in disc degeneration. J Bone Joint Surg Am 77A: 26-31.

Khan IM, Palmer EA, Archer CW (2010) Fibroblast growth factor-2 induced chondrocyte cluster formation in experimentally wounded articular cartilage is blocked by soluble Jagged-1. Osteoarthrits Cartilage 18: 208-219.

Khoshfetrat AB, Kino-Oka M, Takezawa Y, Yamamoto T, Sugawara K, Taya M (2009) Seeding density modulates migration and morphology of rabbit chondrocytes cultured in collagen gels. Biotechnol Bioeng 102: 294-302.

Kim J, Lee EH, Yook JI, Han JY, Yoon JH, Ellis GL (2000) Odontogenic ghost cell carcinoma: A case report with reference to the relation between apoptosis and ghost cells. Oral Surg Oral Med Oral Pathol90: 630-635.

Kobayashi S, Meir A, Urban J (2008) Effect of cell density on the rate of glycosaminoglycan accumulation by disc and cartilage cells in vitro. J Orthop Res 26: 493-503.

Kroemer G, El-Deiry WS, Golstein P, Vaux D, Vandenabeele P, Zhivotovsky B, Blagosklonny MV, Malorni W, Knight RA, Piacentini M, Nagata S, Melino $\mathrm{G}$ (2005) Classification of cell death: recommendations of the Nomenclature Committee on Cell Death. Cell Death Differ 12: 1463-1467.

Le Maitre C, Freemont AJ, Hoyland JA (2007) Accelerated cellular senescence in degenerate intervertebral discs: a possible role in the pathogenesis of intervertebral disc degeneration. Arthritis Res Ther 9: R45.

Lotz JC, Chin JR (2000) Intervertebral disc cell death is dependent on the magnitude and duration of spinal loading. Spine 25: 1477-1483.

Maroudas A, Stockwell RA, Nachemson A, Urban J (1975) Factors involved in the nutrition of the human lumbar intervertebral disc: cellularity and diffusion of glucose in vitro. J Anat 120: 113-130.

Nachemson A, Lewin T, Maroudas A, Freeman MAR (1970) In vitro diffusion of dye through the end-plates and the annulus fibrosus of human lumbar inter-vertebral discs. Acta Orthop Scand 41: 589-607.

Naseer MI, Zubair H, Ikramulla, Kim MO (2009) Effect of fetal calf serum on cellular proliferation of mouse Y1 adrenocortical cells in vitro Pak J Med Sci (Part - II) 25: 500-504.

Neidlinger-Wilke C, Liedert A, Wuertz K, Buser Z, Rinkler C, Kafer W, Ignatius A, Claes L, Roberts S, Johnson WE (2009) Mechanical stimulation alters pleitrophin and aggrecan expression by human intervertebral disc cells and influences their capacity to stimulate endothelial migration. Spine 34: 663-669.

Neuhuber B, Swanger SA, Howard L, Mackay A, Fischer I (2008) Effects of plating density and culture time on bone marrow stromal cell characteristics Exp Hematol 36: 1176-1185.

Ohshima H, Urban JPG (1992) The effect of the lactate and $\mathrm{pH}$ on proteoglycan and protein synthesis rates in the intervertebral disc. Spine 17: 1079-1082.

Park J-B, Chang H, Kim K-W (2001a) Expression of Fas ligand and apoptosis of disc cells in herniated lumbar disc tissue. Spine 26: 618-621.

Park S-H, Choi H-J, Lee J-H, Woo C-H, Kim J-H, Han H-J (2001b) High glucose inhibits renal proximal tubule cell proliferation and involves $\mathrm{PKC}$, oxidative stress, and TGF-ß1. Kidney Int 59: 1695-1705.

Pratsinis H, Kletsas D (2007) PDGF, bFGF and IGF-I stimulate the proliferation of intervertebral disc cells in vitro via the activation of the ERK and Akt signaling pathways. Eur Spine J 16: 1858-1866.

Roberts S (2001) Disc morphology in health and disease. Biochem Soc Trans 30: 864-869.

Roberts S, Evans EH, Kletsas D, Jaffray DC, Eisenstein SM (2006a) Senescence in human intervertebral discs. Eur Spine J 15: S312-S316.

Roberts S, Evans H, Trivedi J, Menage J (2006b) Histology and pathology of the human intervertebral disc. J Bone Joint Surg 88-A: 10-14.

Roberts S, Urban JPG, Evans H, Eisenstein SM (1996) Transport properties of the human cartilage endplate in relation to its composition and calcification. Spine 21: 415-420.

Serigano K, Sakai D, Hiyama A, Tamura F, Tanaka M, Mochida J (2010) Effect of cell number on mesenchymal stem cell transplantation in a canine disc degeneration model. J Orthop Res 28: 1267-1275.

Sharp CA, Roberts S, Evans H, Brown SJ (2009) Disc cell clusters in pathological human intervertebal discs are associated with increased stress protein immunostaining. Eur Spine J 18: 1587-1594.

Sitte I, Kathrein A, Pfaller K, Pedross F, Roberts S (2010) Intervertebral disc cell death in the porcine and human injured cervical spine after trauma. Spine 34: 131140 .

Tanaka A, Okamoto M, Yoshizawa D, Ito S, Gonzalez P, Ide F, Kusame K (2007) Presence of ghost cells and the Wnt signaling pathway in odontomas. J Pathol Med 36: 400-404.

Trout JJ, Buckwalter JA, Moore KC (1982) Ultrastructure of the human intervertebral disc: II. Cells of the nucleus pulposus. Anat Rec 204: 307-314.

Urban JPG, Smith S, Fairbank JCT (2004) Nutrition of the intervertebral disc. Spine 29: 2700-2709.

Waddell G (1996) Keynote address for primary care forum: Low back pain: a twentieth century health care enigma. Spine 21: 2820-2825.

\section{Discussion with Reviewers}

Reviewer II: What is the appropriate cell density for NP cells in alginate bead culture system based on the data? Is it somewhere between $2.5-5 \times 10^{5}$ ?

Authors: This study demonstrates that the optimal cell density for NP cells in alginate culture systems clearly depends on levels of serum and glucose supplementation, at least in terms of cell growth and viability.

Reviewer II: Is there clear evidence that cell clustering seen in vitro culture is the same as the clusters seen in degenerate discs?

Authors: There is some evidence of similarity between in vitro and in vivo clusters. In both situations, cell clusters are likely to arise through clonal expansion, as indicated by the patterns of Ki-67 immunostaining (Johnson et al., 
2001, text reference, and the present work). In addition apoptotic cells also occur in clusters in vivo (Park et al., 2001a, text reference).

Reviewer II: If so, should it be considered as mild to moderate or moderate to severe degeneration?

Authors: This is a difficult issue to comment on with any certainty. Pritzker (1977) (additional reference) states that in the disc these 'cell groups resembled regenerative cell nests in osteoarthritic cartilage'. We would suggest from purely personal observations that small clusters might be representative of mild to moderate degeneration whilst larger, more extensive clusters might be more typical of later stages of degeneration.

Reviewer II: From a cell biology point of view, when cells have the capability to proliferate, the tissue is still responding and could regenerate by itself. This is not the assertion made by others and the authors in previous publications. Please comment about this in the context of the current study.

Authors: We suggest (but do not have proof) that NP cells may respond to degenerative changes in the IVD by initially proliferating to form clusters, as a part of an attempted repair process, but that this may then lead to increased cell death through apoptosis. Hence, overall there is a failure to regenerate the tissue. There are suggestions in the articular cartilage field that a similar sequence of events could occur there also.

\section{Additional Reference}

Pritzker KP (1977) Aging and degeneration in the lumbar intervertebral disc. Orthop Clin North Am 8: 65-77. 